\title{
Learning to swim with the Griffiths tide
}

\author{
G J SMITH, D H MAKINSON, S C FARROW
}

For some time- and more so since the Griffiths inquiry ${ }^{1}$ - the range and volume of management training opportunities for doctors have increased. In most regions in the United Kingdom optional courses are offered yet many doctors are appointed as consultants without any management education and training. The need for more formal management training has been advocated by Parkhouse ${ }^{2}$ and more recently the Association for the Study of Medical Education has endorsed the idea of developing systematic training. ${ }^{3}$ What is required is a programme that regards management training not as an option but as an integral part of the senior registrars' training programme.

It is natural that the belief we have in making sure that clinicians can contribute effectively to management should be reflected in our approach to their training. Each year around 30 senior registrars are trained in Wales; while there are many professional pressures on them the pressure stemming from an awakening interest in management cannot be avoided. This interest is displayed by the senior registrars themselves but equally by their consultants, who are finding themselves increasingly concerned in management at unit and district level. Such is the support from the medical community that we have been able to make time in the existing senior registrars' training programme in Wales for a "Cook's tour" (half days of discussions and visits) and for two residential weeks to be set aside.

We formed a self selected team that began to discuss the inadequacies of the then current training programme early in 1984. It was clear that attendance at future programmes would depend largely on the willingness of existing consultants and health authorities to release senior registrars. Both would be concerned that time spent away from clinical training would be worth while. The cost had to be discussed as well as the perceived benefits. Early soundings were taken that proved hopeful and a formal meeting of the Joint Advisory Committee on Senior Registrars' Training supported the idea in principle. There were several caveats: no management jargon, no sociological nonsense, no more than ten days over four years. Later in 1984 a half day workshop was held with participants invited to prepare brief papers on the course content. The departments with prior experience in management training were asked to prepare a blueprint, and these presentations were followed by eight personal views, four from chief officers in various health authorities - an administrator, treasurer, nursing officer, and community physician-and four from clinicians-a consultant physician, consultant surgeon, senior registrar, and a unit medical representative, also a consultant surgeon.

Generally the contributions focused on the importance of developing the senior registrars' knowledge and skills: knowledge of National Health Service resources, of health care planning, of the interdependence of various health professionals, of performance indicators, of trends in disease patterns; and skills in leadership, in

Nottingham Health Authority, Nottingham NG3 5AF

G J SMITH, MA, MIPM, district personnel officer

University of Wales College of Medicine, Cardiff CF4 4XN

D H MAKINSON, MB, FRCP, director and dean of postgraduate studies

$S$ C FARROW, MD, MRCP, senior lecturer in epidemiology and community medicine

Correspondence to: Dr Makinson. teamwork, in delegation, in negotiation, in evaluating technology, and in organising clinical practice.

The clinicians emphasised the problems that they had personally encountered since their appointment as consultants and discussed what they saw as essential elements in any training programme. They recognised the need to make choices, but with a strong emphasis on the need for the clinician to win. This would require an understanding of the real politik and of the tactics of winning friends and influencing people. One point of view was put across forcefully that management training should begin with clinical management and should include such elements as control of drug costs, equipment and supply policies, admission and discharge policies, and inpatient and outpatient investigation and treatment policies. The unit medical representative focused on the need to keep management training simple; to concentrate on the nuts and bolts issues. Like with first aid the basics tended not to be taught to doctors in training. Many were totally unable to read a balance sheet. They did not know the difference between capital and revenue.

Discussions showed that the proposed format of two blocks of management training would need to be supplemented by a continuing programme of contact, preferably with a management tutor, whom we have termed mentor. After the workshop the following programme was developed.

\section{What is the programme?}

The senior registrars' training programme in Wales is normally four years. Although some senior registrars leave earlier to take up consultant posts in specialties such as anaesthetics and radiology, nearly all will spend over three years in senior registrar training. During this period a three element programme will take place.

\section{TESTING THE TEMPERATURE OF THE WATER}

This title will be familiar to many administrators and treasurers who have been on a Cook's tour as part of their training, and which in Wales is likely to feature in the management training programmes of other professionals. We aim to expose senior registrars to an inside view of a range of functions and departments-generally hospital based-that doctors do not generally see or have the chance to understand. The Cook's tour amounts to a series of around 15 half days in various departments, together with follow up discussions with a nominated unit administrator who will act as mentor. Unit administrators have been invited to take part and all have agreed. The intention is that doctors will gain an understanding of the nonmedical functions of the NHS. The departments have been selected from a handbook for managers, ${ }^{4}$ which makes use of extracts from the Hoare report, ${ }^{5}$ and from documents issued by the National Staff Committee for Administrative and Clerical Staff.

Senior registrars are invited to choose 15 from a list of 26 departments, which includes, for example, nursing, medical records, physiotherapy, pharmacy, social work, and works and management services. Several of these have been designated as core departments (table I). For each department selected there is a list of questions that the senior registrar should answer so that they can be discussed with the unit administrator (mentor) at quarterly tutorials. 
TABLE I- "Departments" included in Cook's tour

\begin{tabular}{lll}
\hline Accident and emergency & Laundry & Planning \\
Administration & Management services & Portering \\
Audiology & Medical records & Radiology \\
Catering & Nursing & Social work \\
Central sterile supplies & Optics/orthoptics & Speech therapy \\
Community services & Pathology & Supplies \\
Domestic & Personnel & Theatres \\
Electrocardiography & Pharmacy & Works \\
Family practitioner & Physiotherapy & \\
& &
\end{tabular}

$\star^{\star}$ Core departments.

TABLE II-Management development for senior registrars in Wales *

\begin{tabular}{|c|c|c|c|c|c|c|c|c|}
\hline \multirow[b]{2}{*}{ Intake year } & \multirow[b]{2}{*}{ No } & \multicolumn{7}{|c|}{ Management development activity } \\
\hline & & 1985 & 1986 & 1987 & 1988 & 1989 & 1990 & 1991 \\
\hline 1983 & 31 & A & B & & & & & \\
\hline 1984 & 44 & & A & B & & & & \\
\hline 1985 & say 30 & & $\begin{array}{l}\text { Cook's } \\
\text { tour }\end{array}$ & A & B & & & \\
\hline 1986 & say 30 & & & $\begin{array}{l}\text { Cook's } \\
\text { tour }\end{array}$ & A & B & & \\
\hline 1987 & say 30 & & & & $\begin{array}{c}\text { Cook's } \\
\text { tour }\end{array}$ & A & B & \\
\hline 1988 & say 30 & & & & & $\begin{array}{c}\text { Cook's } \\
\text { tour }\end{array}$ & A & B \\
\hline
\end{tabular}

*In most cases two A courses and two B courses will be offered each year.

$\mathrm{A}=$ Learning to swim. $\mathbf{B}=$ Advanced strokes.

In the medical records department, for instance, the following questions would be asked. How is a record for a new inpatient or outpatient created? What are the basic documents? How are these added to during the course of the patient's treatment? How are the records stored? What is the role of the medical records department in the compilation of daily bed states, hospital activity analysis, the hospital inpatient inquiry, the monitoring of waiting lists? What are the implications of the Körner report? How long are records kept?

A visit to the physiotherapy department would be aimed at answering the following questions. Does the department accept direct references from general practitioners? What is the role of the physiotherapist in determining the type of care for individual patients? Is there any participation in community physiotherapy? Within the supplies section the senior registrar should become familiar with the types of goods purchased and where these are stored. Are goods purchased using national, regional, interdistrict, or local contracts? Why does the hospital purchase 15 different types of $x$ ray film to meet various user needs?

\section{LEARNING TO SWIM}

In the second year senior registrars spend one residential week on a course that allows them to work through some of the knowledge, skills, and attitudinal elements that are, or should be, commonplace for anyone calling himself a manager. Particular emphasis is given to the basic principles underlining the NHS, together with descriptions of structure and function of the service. Attention is given to the role of clinician and the elements of the management structure and process with which clinicians have the greatest contact. The intention of this is to help participants learn to swim so that they may keep their heads above the management waves in which they will work when consultants.

\section{STROKES}

The management course in the third year of training lasts a further week. The aim is to increase the participant's knowledge and understanding of a range of management theories and techniques that are of most relevance to practising clinicians.

Both courses have some common features. They include a high level of participation, a mixture of teaching, discussion, exercises, and examples and issues that are highly relevant to the environment in which clinicians operate. Several contributions will be made by practising clinicians and others who have a particular interest in the health service-for example, general managers and chairmen.

By the end of the training programme senior registrars should have a good grasp of the way that decisions are taken and should have acquired several interpersonal skills. These include the skills of managing people-for example, the chairing of meetings and group decision making-of managing resources, and of managing information.

There is scope for change and improvement. The advanced strokes course might be better learnt in a multidisciplinary setting and the orientation might change with closer negotiation with general practitioners in training.

At the annual review of senior registrars' progress they will be expected to submit an account of their management activities. The mentor will be invited to submit a report in the same way as the clinical consultants.

\section{How has this all been possible?}

The prime movers have been the senior registrar training committee centred on the postgraduate department of the University of Wales College of Medicine-the medical school for Wales - and the All Wales Personnel Committee, set up by health authorities to deal with personnel matters best handled on an all Wales basis. These two bodies have recognised the joint strength of building on the existing infrastructure for medical education, by the addition of the collective support of health authorities and its central personnel organisation.

There have, however, been some important partners. The Chief Medical Officer of the Welsh Office has supported the initiative, as has the chairman of the Welsh Medical Committee. Our ideas have been shaped by those with previous experience of teaching management to senior registrars. These include the professors of community medicine and of anaesthetics of the University of Wales College of Medicine and the professors of business administration and accountancy of the University of Wales Institute of Science and Technology, whose department is developing the course elements. We have also had financial support from the National Health Service Training Authority. The major funding comes from the All Wales Personnel Committee and includes the payment for preparation of course materials, for course fees, and for accommodation and travel for the participants.

The full programme starts with the senior registrar intake for 1985 , but there is a catch up opportunity for some earlier intakes to cover the course elements (table II). Some of those attending will have recently been appointed to consultant posts. Each senior registrar receives an introduction letter from the postgraduate dean, explaining the requirement to undertake the management development programme. The course will normally be taught in small groups of about 15 .

Our success can be judged only when the management process is enhanced by the contributions that ex-trainees make, but in the early stages we will be modifying our ideas and the programme to take account of comments of participants and of their consultants.

There is scope for several initiatives in management education and training for clinicians. What we have done is to make management training an important part of the standard programme for the senior registrars who undertake their training in Wales.

\section{References}

NHS Management Enquiry. Report. London:DHSS, 1983. (Griffiths report.)

2 Parkhouse J. Medical education and management. Med Educ 1983;17:213-5.

3 Parry KM. The education of clinicians in health services management. Med Educ 1985;19:68-75.

4 Welsh Management Training Scheme. Handbook for managers. Cardiff: Administrators' Training Liaison Group, 1983

5 National Staff Committee for Administration and Clerical Staff. The recruitment and career development of administrators. London: National Staff Committee for Administrative and Clerical Staff, 1979

(Accepted 15 October 1985) 